\title{
PEMANFAATAN GARAM KROSOK SEBAGAI KREATIF BISNIS MASYARAKAT PESISIR
}

\section{UTILIZATION OF SALT KROSOK AS A CREATIVE OF COASTAL BUSINESS COMMUNITIES}

\author{
Rika Diananing Putri ${ }^{*}$, R. Amilia Destryana ${ }^{2}$, Ribut Santosa ${ }^{3}$ \\ ${ }^{1,2)}$ Prodi. Teknologi Hasil Pertanian, Universitas Wiraraja \\ ${ }^{3)}$ Prodi. Agribisnis, Universitas Wiraraja \\ email: rikadepe@wiraraja.ac.id
}

\begin{abstract}
Salt is one of the results of evaporation of sea water into solid granules, which are used as a supplementary spice that can give a savory taste. . Coastal communities still produce salt using traditional methods and the results (salt) are sold in the form of krosok salt which is packaged using sacks weighing $70 \mathrm{~kg} /$ sack and sold for Rp. $1500 / \mathrm{kg}$. The purpose of this research is to optimize the use of krosok salt into high-value products and provide benefits for the wearer. Crude salt is not only used as a supplementary material in the kitchen, but with our technology, processing salt is useful in the field of health and beauty. Descriptive research methods, and data collection through observation (survey), interviews and literature studies. We can conclude that krosok salt can provide business value and increase income for coastal communities.
\end{abstract}

Keywords: Creative bussiness, coastal communities, salt

\begin{abstract}
ABSTRAK
Garam merupakan salah satu hasil dari penguapan air laut menjadi butiran padat, yang digunakan sebagai bumbu pelengkap yang dapat memberikan rasa gurih. . Masyarakat pesisir memproduksi garam masih menggunakan cara tradisional dan hasilnya (garam) dijual dalam bentuk garam krosok yang dikemas menggunakan karung dengan berat 70kg/karung dan dijual Rp. 1500/kg. Tujuan penelitian untuk mengoptimalkan penggunaan garam krosok menjadi produk yang bernilai jual tinggi dan memberikan manfaat bagi pemakainya. Garam krosok bukan hanya dimanfaatkan sebagai bahan pelengkap di dapur, tetapi dengan teknologi kita mengolah garam krosok menjadi bermanfaat dalam bidang kesehatan dan kecantikan. Metode penelitian deskriptif, dan pengambilan data melalui metode pengamatan (survey), wawancara dan studi literatur. Dapat kita simpulkan garam krosok dapat memberikan nilai bisnis dan menambah pendapatan bagi masyarakat pesisir.
\end{abstract}

Kata Kunci: Garam, Kreatif Bisnis, Masyarakat Pesisir

\section{PENDAHULUAN}

Garam merupakan salah satu kebutuhan pelengkap dari kebutuhan pangan dan sumber elektrolit bagi tubuh manusia serta garam hasil dari penguapan air laut menjadi butiran padat, yang digunakan sebagai bumbu pelengkap yang dapat memberikan rasa gurih. Kandungan garam yang utama Natrium Clorida $(\mathrm{NaCl})$ dan zat pengotor terdiri dari $\mathrm{CaSO}_{4}, \quad \mathrm{MgSO}_{4}, \quad \mathrm{MgCl}_{2}$ dan lain-lain. Menurut (Rositawati, Taslim, \& Soetrisnanto, 2013) menyatakan pembuatan garam ada bermacam metode yaitu dengan penguapan, penambahan garam dan dari sumur air garam (braine). 
Sebagian besar masyarakat pesisir membuat garam dengan bantuan sinar matahari dengan metode penguapan. Garam terbagi berdasarkan pemanfaatannya yaitu garam konsumsi dan garam industri. Garam konsumsi adalah yang digunakan sebagai bumbu pelengkap, sedangkan garam industri adalah garam yang digunakan untuk membantu pada proses industri seperti pada bidang pabrikasi, medis, dan bahkan untuk kecantikan. Garam sebagian besar dijual dalam harga yang minim yaitu $\mathrm{Rp}$. 1500/kg dalam bentuk garam krosok, dan pendapatan masyarakat khususnya pesisir hanya Rp. 200.000,- per bulan. Meskipun garam termasuk kebutuhan pokok pangan namun garam hanya dibutuhkan dalam jumlah sedikit. Oleh sebab itu pengeluaran masyarakat untuk pembelian garam masih dinilai rendah (BPS, 2016).

Garam krosok merupakan kualitas tiga dengan kandungan Magnesium lebih tinggi dibandingkan dengan garam dapur dan masih belum ada tambahan iodium, dan masyarakat (petambak garam) menjual garam krosok dengan harga yang minim. Untuk permasalahan tersebut, maka dapat dilakukan penelitian terhadap pemanfaatan garam krosok yang dijadikan sebagai bahan dasar pembuatan bidang kecantikan.

Pemanfaatan garam krosok dapat meningkatkan nilai ekonomi masyarakat pesisir khususnya dan juga daerah penghasil garam umumnya. Meningkatnya nilai ekonomi pada produk garam maka meningkatkan juga pendapatan yang dapat mensejahterakan masyarakat pesisir. Hal tersebut menjadi salah satu upaya dalam memberdayakan masyarakat pesisir secara berkelanjutan melalui inovasi produk berbasis hasil pesisir yaitu garam krosok
(Ilham Marasabessy1, Achmad Fahrudin, 2018). Tujuan penelitian ini untuk mengoptimalkan penggunaan garam krosok menjadi produk yang bernilai jual tinggi dan memberikan manfaat bagi pemakainya serta mendukung wisata bahari. Penggunaan garam laut yang salah satunya adalah garam krosok dapat meningkatkan nilai tambah melalui pemanfaatan menjadi garam batch (Rositawati et al., 2013).

\section{METODE PENELITIAN}

Penelitian dilaksanakan di desa Gersik Putih Kecamatan Gapura. Metode penelitian yaitu deskristif. Penelitian deskriptif merupakan penelitian dengan cara mendeskripsikan hasil agar menjadi informasi yang jelas(Jumiarni \& Komalasari, 2017).

Metode pengambilan data dilakukan melalui pengamatan (survey), wawancara dan studi literatur. data hasil wawancara maupun kuesioner uji kuesioner selanjutnya ditabulasi dan dideskripsikan menjadi informasi yang mudah untuk difahami.

Pengambilan data berupa data primer yaitu petambak garam dan stakeholder dengan wawancara dan kuesioner (uji kesukaan) terhadap produk, serta untuk data sekunder diperoleh dari studi literatur yang diperoleh dari buku, jurnal, artikel dan data pendukung lainnya.

\section{Alat dan Bahan}

Bahan dan alat yaitu Garam krosok, Esensial oil, Pewarna makanan cair, Minyak zaitun, Asam sitrat, Baking soda, Wadah yang memiliki penutup, sendok kayu, tempat penyimpanan. 
Prosedur pembuatan garam spa sebagaimana pada gambar 1 .

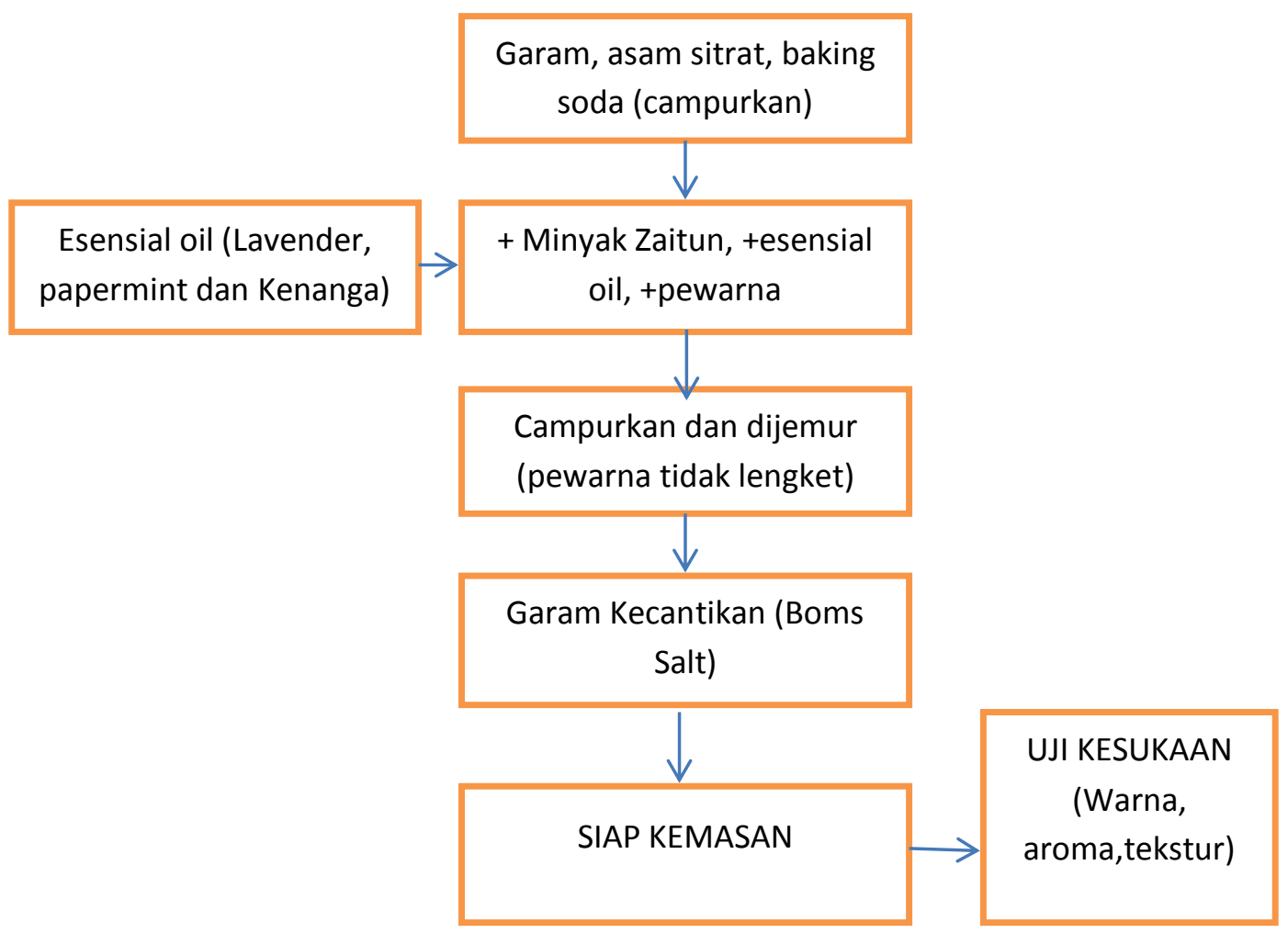

Gambar 1. Diagram Alir Pembuatan Boms Salt

Produk tersebut diuji menggunakan uji hedonik (kesukaan) menggunakan uji panelis sebanyak 25 orang untuk menentukan produksi boms salt. Menurut Waysima dkk dalam (Wahyuningtias, Putranto, \& Kusdiana, 2014) pengujian organoleptik melalui penginderaan manusia yang mengakibatkan reaksi sebagai alat ukur yaitu rasa, warna, aroma, tekstur. (Pratiwi et al., 2017) menyimpulkan bahwa penggunaan esensial oil lebih banyak yang suka.

\section{HASIL DAN PEMBAHASAN}

Garam krosok memiliki kandungan Magnesium yang tinggi dibandingkan garam yang dikonsumsi. Untuk meningkatkan nilai tambah dari garam krosok tersebut, maka dapat diberikan ide kreatif bisnis bagi masyarakat pesisir khususnya kaum perempuan untuk mengolah menjadi produk yang bernilai jual. Menurut (Suwarsono, 2013), kandungan air laut $76,43 \% \leq \mathrm{NaCl} \leq$ $89,90 \%$, sedangkan sampel air laut untuk parameter $\mathrm{Na}+<10 \mathrm{gr} / \mathrm{kg}$ dan $\mathrm{Cl}-<19$ $\mathrm{gr} / \mathrm{kg}$.

Desa gersik putih kecamatan gapura, mengolah garam krosok menjadi garam untuk kecantikan karena diyakini, bahwa garam dapat memberikan manfaat bagi kecantikan. Pengolahan garam menjadi campuran/ untuk merendam dan menghilangkan toksix. Garam diolah menjadi garam boms (Boms Salt) yang dapat memberi manfaat kesehatan tubuh, 
dapat mencerahkan kulit, melembutkan dan melebabkan, memberi aroma wangi serta merevitalisasi tubuh pada masa stress. Pembuatan boms salt : (1). garam+minyak_zaitun, garam+minyak_zaitun +pewarna, dan (3) garam+minyak_zaitun+esensial_oil(pappe rmint), minyak_zaitun+esensial_oil(lavender), garam+minyak_zaitun+esensial_oil(kenan ga). Skala yang dipakai pada produk boms salt ada 6 yaitu amat sangat suka, sangat suka, suka, agak suka, netral, tidak suka, yang tersaji pada tabel 1 .

Tabel 1. Skala hedonik dan numerik pada produk boms salt.

\begin{tabular}{lc}
\hline Skala Hedonik & Skala Numerik \\
\hline Amat sangat suka & 6 \\
Sangat suka & 5 \\
Suka & 4 \\
Agak suka & 3 \\
Netral & 2 \\
Tidak Suka & 1 \\
\hline
\end{tabular}

Dari panelis didapatkan hasil untuk produk boms salt tersaji pada tabel 2 dibawah ini.

Tabel. 2. Rata-rata skor uji hedonik/kesukaan pada boms salt

\begin{tabular}{lccc}
\hline \multirow{2}{*}{ Jenis Produk } & \multicolumn{3}{c}{ Rata-rata uji hedonik } \\
\cline { 2 - 4 } & Aroma & Warna & Tekstur \\
\hline garam+minyak_zaitun & 2,75 & 2,75 & 2,75 \\
garam+minyak_zaitun +pewarna & 2,75 & 3,5 & 3,25 \\
garam+minyak_zaitun+esensial_oil(pappermint) & 5,75 & 5,75 & 5,75 \\
garam+minyak_zaitun+esensial_oil(lavender) & 3,25 & 3,25 & 5,25 \\
garam+minyak_zaitun+esensial_oil(kenanga) & 5,5 & 5,5 & 5,5 \\
\hline
\end{tabular}

*data primer

Berdasarkan tabel 2, panelis lebih menyukai penggunaan esensial oil (pappermint) baik dari aroma, warna dan tekstur boms salt karena memberikan efek relaksasi pada tubuh. (Pratiwi et al., 2017) menjelaskan pappermint dapat memberikan relakasasi dan meringankan stress.

Dari hasil uji kesukaan dapat kita lanjutkan pada analisa usaha pda kelayakan usaha produk boms salt. Usaha kreatif bisnis pada produk olahan garam (boms salt) menunjukkan bahwa produk boms salt menguntungkan dari pendapatan dan RC Rasio. Hasil yang diperoleh dari tabel 2 adalah nilai rata-rata tertinggi pada formulasi penambahan minyak zaitun dan esensial oil (pappermint) dengan nilai ratarata pada aroma, warna dan tekstur.

\section{KESIMPULAN DAN SARAN}

Pemanfaatan garam krosok memberikan nilai ekonomi bagi masyarakat pesisir yang ditunjukkan pada olahan produk boms salt. Melalui uji kesukaan, produk dengan formulasi garam+minyak_zaitun+esensial_oil(pappe rmint) karena dapat memberikan relaksasi dan menurunkan tingkat strees. Dan secara keuntungan dan kelayakan usaha, produk 
ini sangat layak karena NPV bernilai positif dan pengembalian kurang dari satu tahun.

\section{DAFTAR PUSTAKA}

BPS. (2016). Pengeluaran untuk Konsumsi Penduduk Indonesia. Badan Pusat Statistik Indonesia.

Ilham Marasabessy1, Achmad Fahrudin, Z. I. \& S. B. A. (2018). Strategi Pengelolaan Berkelanjutan Pesisir dan Laut Pulau Nusa Manu dan Pulau Nusa Leun di Kabupaten Maluku Tengah, 2(1), 1-22.

Jumiarni, W. O., \& Komalasari, O. (2017). Masyarakat Suku Muna Di Permukiman Kota Wuna Inventory of Medicinal Plants As Utilized By Muna Tribe in. Traditional Medicine, 22(April), 45-56.

Pratiwi, D. M. N., Dewi, P. P. P.,
Wilantari, P. D., Cornelia, N. K., Trisna, A., Putra, I. P. Y. A., \& Laksmiani, N. P. L. (2017). Uji Hedonik Produk Foot Scrub Menggunakan Kulit Buah Naga Merah dan Air Rebusan Daun Pepaya, 6, 62-66.

Rositawati, A. L., Taslim, C. M., \& Soetrisnanto, D. (2013). DIVERSIFIKASI GARAM LAUT MENJADI GARAM MANDI BATH BOMBS, 2(4), 217-225.

Suwarsono, B. (2013). Laporan akhir penelitian unggulan perguruan tinggi.

Wahyuningtias, D., Putranto, T. S., \& Kusdiana, R. N. (2014). UJI KESUKAAN HASIL JADI KUE BROWNIES DAN TEPUNG GANDUM UTUH Landasan Teori, 57-65. 